\title{
O pochodzeniu i rozwoju semantycznym leksemu pluta jako przykładzie zbieżności polsko-uschodniosłowackich w leksyce meteorologicznej
}

Słowa kluczowe: pluta, dialekty wschodniosłowackie, etymologia, terminologia meteorologiczna.

doi: http://dx.doi.org/10.31286/JP.101.3.9

Przedmiot artykułu stanowi analiza północnosłowiańskiego (dalej: płnsłow.) leksemu * pluta 'słota, niepogoda', należącego do grupy leksyki opisującej zjawiska meteorologiczne. Praca ma na celu zestawienie informacji na temat etymologii oraz rozwoju semantycznego omawianego wyrazu, określenie zasięgu jego występowania w językach słowiańskich oraz zbadanie relacji polskiego leksemu ze wschodniosłowackim (dalej: wschsła.) pluta/pluta 'zła pogoda, w czasie której mają miejsce opady deszczu połączone z wiatrem' oraz z jego odpowiednikami w innych językach słowiańskich. W tekście został omówiony przykład wspólnej dla badanego obszaru jednostki leksykalnej określającej deszczową pogodę. Analiza leksykalno-semantyczna została przeprowadzona na podstawie materiału słownikowego (przede wszystkim polskiego i słowackiego, ale także innych języków północnosłowiańskich). W pracy wykorzystano również dane zawarte w atlasach językowych i kartotekach słowników. Niniejszy artykuł powstał na podstawie badań nad zbieżnościami leksykalnymi, które łączą język polski z dialektem wschodniosłowackim, i nawiązuje do tekstu opublikowanego przeze mnie na łamach „Języka Polskiego” w 2019 roku (Pogwizd 2019). Zachętą do podjęcia tej tematyki była ożywiona dyskusja na temat licznych elementów polskich (względnie lechickich) w dialekcie wschodniosłowackim, którą zainicjowano na początku XX wieku. Swoje poglądy na ten temat wyrażało wielu wybitnych slawistów (Stanislav 1935; Stieber 1950; Krajčovič 1974: 13-28; Štolc 1994: 140-143; Bednarczuk 2018: 178-185).

Określenia dotyczące zjawisk atmosferycznych stanowią jedną z najstarszych warstw słownictwa. Na obszarze całej Słowiańszczyzny bardzo często są to terminy o zasięgu ogólnosłowiańskim, wywodzące się jeszcze z doby wspólnoty prasłowiańskiej. Z taką właśnie sytuacją mamy do czynienia w gwarach polskich oraz w dialekcie wschodniosłowackim. Warto jednak zaznaczyć, że część wyrazów występuje wyłącznie na tym terenie lub odznacza się odrębnym

* szymon.pogwizd@ispan.waw.pl; ORCID: oooo-0oo3-4397-2478 
od pozostałych języków słowiańskich rozwojem semantycznym. We wschodniosłowackim słownictwie meteorologicznym można zaobserwować kilka interesujących zbieżności łączących ten obszar z językiem polskim. Jedną z nich jest paralelny rozwój pol. pluta oraz wschsła. plutalpluta.

Władysław Kupiszewski - twórca pracy prezentującej zróżnicowanie geograficzne polskiej leksyki meteorologicznej na tle historycznym - omawia w niej między innymi grupę leksykalno-semantyczną SŁOTA, w której skład wchodzą leksemy określające trwającą przez dłuższy czas deszczową pogodę, szarugę jesienną bądź deszcz ze śniegiem. Autor zwraca uwagę na duże zróżnicowanie leksykalne i słowotwórcze w obrębie tej grupy. Oprócz najpopularniejszego we współczesnej polszczyźnie leksemu słota funkcjonowały również inne synonimiczne nazwy, takie jak: plucha, plusk, pluskota oraz już staropolska (dalej: stpol.) pluta, która obejmowała zasięgiem występowania znaczny obszar Polski (Kupiszewski 1969: 36-38, 119). O miejscu pluty wśród innych pokrewnych wyrazów W. Kupiszewski pisze w następujący sposób:

Do tej samej grupy [co plucha i pluskota - dop. S.P.] należą pokrewne etymologicznie pluta (tworząc zwarty obszar na zachodzie i północy Polski, sGP [Karł - dop. S.P.] podaje ją z Kujaw, Lubelskiego i Podhala), jej wariant fonetyczny fluta, następnie plucisko, plugawina i plugota. Pluta podobnie jak pluskota, znana była i często używana w dawnej polszczyźnie [...] (1969: 37).

Słowo pluta w znaczeniu 'deszcz, słota, pluvia, imber' było notowane w języku staropolskim już od XV wieku (sstp, t. 6: 154). W sstp ujęto jedno poświadczenie z 1466 roku, które stanowi glosę w polskiej średniowiecznej poezji spisanej w języku łacińskim. Zostało ono zaczerpnięte z pracy Aleksandra Brücknera na ten temat. Polski wyraz pluta 'nimbus' pojawia się w rękopisie Marcina z Łęczycy (Brückner 1895: 26). Słowo jest notowane także w słownikach dokumentujących późniejsze dzieje polszczyzny (np. SPXVI, t. 24: 363; L, t. 4: 168). Obecnie w języku polskim słowo pluta ma charakter archaizmu lub regionalizmu stanowiącego synonim ogólnopolskiego plucha 'długotrwały deszcz, brzydka, dżdżysta pogoda, słota, szaruga' (sJPDor, t. 6:481). Najnowsze słowniki współczesnej polszczyzny raczej już nie odnotowują tego wyrazu (np. sWJP; WSJP PAN). Leksem w dialektach ma niemalże ogólnopolski zasięg, na co wskazują liczne poświadczenia. Obszerny materiał gwarowy przytacza w swoim słowniku Jan Karłowicz, podając przykłady użycia wyrazu z Kujaw, Mazowsza, Lubelszczyzny, Małopolski (gwara zebrzydowska, Podhale), a także poświadczenia kaszubskie (SGPKarł, t. 4: 128). Wiedzę na temat geografii wyrazu uzupełnia kartoteka Stownika gwar polskich PAN (SGP PANKart), gdzie można ponadto znaleźć dowody obecności wyrazu na Kociewiu (Leśna Jania), w Wielkopolsce (np. Wieleń, Kramsk), na Śląsku Cieszyńskim (także w gwarach polskich sięgających poza granicę państwa, na tzw. Zaolziu), Śląsku Opolskim (por. też: Pluta 1973: 115), Górnym Śląsku, Podkarpaciu, Kielecczyźnie (SGP PANKart; SGPKarł, t. 4: 128). Zebrany materiał wzbogacają ponadto liczne słowniki gwarowe poszczególnych regionów (np. SGM, t. 2: 21).

Słowacki dialektalny wyraz pluta/pluta 'zła pogoda, podczas której mają miejsce opady deszczu połączone z wiatrem' został ujęty w czwartym tomie Atlasu języka słowackiego, poświęconym leksyce (ASJ, t. 4: 27; ASJKom: 44). We wspomnianej pozycji rozpatruje się zróżnicowanie nazw określających czas deszczowej i wietrznej pogody. Zasięg występowania słowa pluta/pluta obejmuje cały obszar dialektu wschodniej Słowacji. Wyrazowi badanemu przez nas 
odpowiada ogólnosłowackie plušt. Analogiczne znaczenie podaje także Ferdinand Buffa, autor słownika gwary szaryskiej, należącej do dialektu wschodniosłowackiego (2004: 209). Również Słownik gwar słowackich rejestruje hasło pluta 'trwająca przez dłuższy czas słotna, deszczowa pogoda, niepogoda' (ssN, t. 2: 843). Leksem jest używany także w północnej części dialektu środkowosłowackiego, znajdującej się blisko granicy z gwarami polskimi (głównie na Orawie) oraz w gwarach górnotrenczyńskich i kysuckich (należących już do grupy dialektów zachodniosłowackich). Na obszarach położonych na południe od wskazanego obszaru funkcjonują ogólnosłowackie (dalej ogsła.) plušt'lub čas zlí (planí, mrxaví) (ASJ, t. 4: 27). Zagadnienie zróżnicowania leksemów określających niepogodę w dialektach słowackich omawia szczegółowo w swojej pracy Adriana Ferenčíková, wymieniając liczne synonimy plušt', w tym także wyraz pluta (2005: 29-32). Wyraz jest obecny także w słowniku historycznym języka słowackiego (pluta 'trwająca dłużej deszczowa pogoda; synonim ogsła. plušt'), co dowodzi długotrwałej obecności leksemu w gwarach słowackich. Poświadczenia pochodzą z XVII i XVIII wieku z miejscowości zlokalizowanych w północnej Słowacji (Beckov w województwie trenczyńskim oraz Martin). Położenie tych miejscowości pokrywa się z zasięgiem występowania badanego wyrazu określonym w Atlasie języka słowackiego (HSSJ, t. 3: 558). Obecność leksemu w gwarach słowackich potwierdza także słownik Kálala wydany w latach dwudziestych ubiegłego wieku (1924: 475) oraz Slovník slovenského jazyka z jego drugiej połowy (SSJ, t. 3: 99).

Poza językiem polskim i dialektem wschodniosłowackim odpowiedniki wyrazu w tym znaczeniu znajdujemy także w innych językach zachodniosłowiańskich. Słowo pluta 'deszczowa pogoda, długotrwały deszcz’ występuje w dialektach języka czeskiego (ssJč, t. 2: 622). Jego zasięg ogranicza się jednak do gwary laskiej (mającej charakter gwary przejściowej) oraz wałaskiej (Bartoš 1906: 295-296; Kazmír 2001: 252). Istnieje zatem prawdopodobieństwo, że wyraz trafił do dialektów czeskich za pośrednictwem polskim lub słowackim. Możliwe, że zasięg omawianego wyrazu był jeszcze szerszy, a śladem dawnej obecności w językach łużyckich może być archaiczny dolnołużycki wyraz plut 'powódź' (Muka 1911-1928, t. 2: 82). Zagadnienie rodzimości łużyckiego wyrazu zostanie omówione poniżej.

Warto odnotować, że odpowiedniki omawianego słowa znajdujemy także w językach wschodniosłowiańskich, mianowicie białoruskim i ukraińskim. Wyraz jest dobrze poświadczony w dialektach języka białoruskiego (szczególnie w części zachodniej), na przykład plúta 'niepogoda, słota, plucha' (SPZB, t. 4: 21; Scâškovič 1983: 363). Bogumił Ostrowski, autor pracy poświęconej białoruskim gwarom Grodzieńszczyzny, również odnotowuje leksem plúta, przyporządkowując go do grupy semantyczno-leksykalnej określającej okres długotrwałych opadów deszczu, względnie deszczu ze śniegiem lub topniejącego śniegu (2013: 133-135). Wyraz nie jest notowany w słownikach współczesnego języka białoruskiego, jednakże plúta 'niepogoda’ pojawia się od XVII wieku w źródłach języka starobiałoruskiego (HSBM, t. 24: 388). Ukraińskim odpowiednikiem omawianego wyrazu jest dial. plúta 'niepogoda, plucha, deszczowa pogoda' (sUM, t. 6: 601; Grìnčenko 1958, t. 3: 199; Želehovskij, Nedil'skij 1886, t. 2: 661). Słowo pojawia się już w XVII-wiecznym leksykonie Jepifaniusza Sławyneckiego i Arseniusza Koreckiego-Satanowskiego (1973: 482).

Trzeba zauważyć, że w opinii autorów słownika etymologicznego języka białoruskiego niewystępujący już dziś w języku literackim wyraz plúta 'słota, plucha', 'deszcz ze śniegiem' pojawił 
się pod wpływem języka staropolskiego (ESBM, t. 9: 230; Ostrowski 2013:134). Nie można wykluczyć także możliwości zapożyczenia z polszczyzny ukr. dial. pluta w tym samym znaczeniu.

Pochodzenie pol. pluta oraz jego odpowiedników w innych językach słowiańskich nie zostało w pełni wyjaśnione. W cytowanej powyżej pracy W. Kupiszewski (zapewne pod wpływem Brücknera) uważa podobne pod względem formy wyrazy bliskoznaczne, takie jak pol. dial. plucha, plusk, pluskota (por. także kasz. plësk 'śnieg z deszczem', plusk'otńica 'śnieg z deszczem', pl'ëščóvka 'słota' (SychtaKasz, t. 4: 74-76), ogsła. plušt'zła, deszczowa pogoda' itp. (Králik 2015: 449)) za pokrewne wyrazowi ^ pluta. Powyższe formy najczęściej wywodzi się od psł. dźwiękonaśladowczego * pluskъ!, ${ }^{*}$ pluskati (SEK, t. 4: 71; ESUM, t. 4: 459-460). Trudno jednak uznać za wiarygodne wyjaśnienie Brücknera, który wyprowadza pol. pluta od jednej z synonimicznych form pluskota lub pluchota. Przebieg domniemanej derywacji wydaje się niejasny dla samego autora, który w stosunku do wyrazu pluta używa sformułowania „niby skrócone" (Brückner 1970: 419). Za odrzuceniem tej hipotezy przemawiają brak paralel z takim sposobem tworzenia wyrazów oraz argumenty semantyczne związane z rozwojem płnsłow. *pluta i wyrazów pokrewnych wymienionych poniżej.

Obecnie większość etymologów skłania się ku przypuszczeniu, że leksem * pluta należy wywodzić od pierwotnego ${ }^{\star}$ pleu-t-a, utworzonego od pie. rdzenia ${ }^{*}$ pleu- za pomocą sufiksu -ta (Machek 1957: 379; ESBM, t. 9: 230; ESUM, t. 4: 460; Ostrowski 2013: 134). Julius Pokorny w swoim leksykonie rekonstruuje dla pie. ${ }^{*}$ pleu- następujące znaczenia: 'unosić się na powierzchni wody, płynąć; lać się, ciec, wylewać, przelewać, przeciekać; lać (o ulewnym deszczu); toczyć się; latać, fruwać' (Pokorny 1949-1969, t. 2: 835-837; Sławski 1976: 37). Franciszek Sławski w Zarysie słowotwórstwa prasłowiańskiego charakteryzuje sufiks -ta jako formant prymarny, najczęściej przyłączany do rdzenia werbalnego i zauważa, że wyrazy utworzone za jego pomocą to „zwykle [...] pierwotne nomina actionis, abstrakta werbalne, skonkretyzowane w nomina acti, wyjątkowo w nomina instrumenti" (1976: 41-42). Nieco niżej badacz przytacza w swojej pracy płnsłow. pluta 'powódź, dżdżysta pogoda, słota' jako przykład wyrazu utworzonego za pomocą powyższego przyrostka, wiążąc pochodzenie tego słowa z psł. czasownikiem * pluti (1976: 41). Podobnie na ten temat wypowiada się Hanna Popowska-Taborska, rozpatrując pochodzenie kasz. plëta w Słowniku etymologicznym kaszubszczyzny (SEK, t. 4: 73).

Istotne dla rozważań nad rozwojem badanego wyrazu jest jego prawdopodobne pokrewieństwo z psł. * pluta. Wyraz ten wydaje się homonimem omawianego w tym artykule słowa, utworzonym od innego wariantu tego samego rdzenia. Leksem zawiera ten sam sufiks z podstawowym -t-. W odróżnieniu od form zawierających miękkie l'wyrazy wywodzące się od psł. pluta mają zasięg ogólnosłowiański. Kontynuanty psł. pluta odróżniają się od płnsłow. * pluta odrębną, zawężoną semantyką, nawiązującą do płynięcia, unoszenia się na wodzie. Zwykle oznaczają lekkie przedmioty unoszące się na wodzie, jak: pol. dial. płutal płut/płutko 'lekki przedmiot utrzymujący sieć na powierzchni wody; spławik, część wędki' (przykłady z północnych terenów Polski: Kaszuby, Warmia, Mazury, Kurpie, Wielkopolska; SGP PANKart; SGPKarł, t. 4: 128; SychtaKasz, t. 4: 87), czes. plut 'dąb korkowy' (zapożyczenie z chorwackiego/serbskiego) (ssJČ, t. 2: 622), ros. dial. płut 'spławik w sieci' (SRNG, t. 27: 165), ch./s. plüta/plüto/plúto 'materia pozyskiwana z dębu korkowego' (R.Mat., t. 4: 481), por. też pol. dial. płytko 'część wędki, spławik'. Jak zauważa H. Popowska-Taborska, „w nazwach 
tych poświadczone są stare werbalne rdzenie apofoniczne ${ }^{\star} p l u(t i): p l y(t i)$ 'płynąć” (sEK, t. 4: 80; por. Sławski 1976: 36-37).

Ta sama motywacja, którą można zaobserwować w kontynuantach psł. ${ }^{*}$ pluta, tkwi u podstawy semantyki leksemu * pluta (pol. płuca) pierwotnie nawiązującej do właściwości pozwalających na unoszenie się na wodzie. Wyraz ten występował w prasłowiańszczyźnie w dwóch wariantach fonetycznych: plutelplute n 'płuco, * pluta/pluta mn 'płuca', które W. Boryś wywodzi od pie. praform pleu-tio-/plou-tio-. Badacz łączy wyraz z tym samym, wspomnianym już pie. rdzeniem pleun- (Boryś 2005: 447). Derywat zawiera formalnie takie samo rozszerzenie ${ }^{\star}-t$ -

Semantyka kontynuantów płnsłow. * pluta jest zróżnicowana i często koresponduje ze znaczeniami rekonstruowanymi dla pie. rdzenia * pleun-. Przeważnie wyraz określa długotrwałą złą pogodę połączoną z opadami deszczu (np. podkarp. pluta 'deszczowa pogoda', kielec. ‘jesienny deszcz, błoto, wiatr’; sGP PANKart), najczęściej niesprzyjającą człowiekowi, zagrażającą zdrowiu i plonom. Wyrazowi często towarzyszy silne nacechowanie emocjonalne o charakterze pejoratywnym, co dobrze ilustrują następujące przykłady: pol. „Pluta straszno sie zrobiła, zboże zgnije, nie będzie po co jechać na polé” (SGM, t. 2: 21); „A żniwa były [...] a tu pluta przyszła” (SGP PANKart), sła. „Chto bi tam išol do taki pluti! Ta to pluta! Barz mokro a velo blata a pada diśč. Psa ňehodno vihnat do takej pluti!” (ssN, t. 2: 843). Oprócz powyższego, najbardziej powszechnego znaczenia funkcjonują także inne:

(a) określenie deszczu: młp. pluta 'drobny deszcz' (Biela 1882: 212), młp., podkarp., wlkp. 'deszcz ze śniegiem' (SGP PANKart; SGM, t. 2: 21). Podobnie do samego opadu, a nie złej pogody nawiązują czasowniki denominalne, takie jak kasz. plëcëc 'padać o deszczu', naplëcëc 'napadać' (SychtaKasz, t. 4: 76), ukr. plutíty 'padać (o deszczu)' (Želehovskij, Nedil'skij 1886, t. 2: 661);

(b) określenie brodu: wlkp. plutka 'mały bród' (SGP PANKart);

(c) stawy, sadzawki: wlkp. pluta 'mały stawek' (sGP PANKart), kasz. plëta 'mały staw, małe jezioro’ To błotko to le je takå plëta, lović na plëtax (SychtaKasz, t. 4: 76), 'stawek koło domu dla gęsi i kaczek' (sGP PANKart);

(d) kałuża, bajoro: pol. dial. pluta 'kałuża, woda w zaklęśnięciach drogi stojąca; woda deszczowa niemająca odpływu, bajoro' (SGPKarł IV: 128; SGP PANKart), wlkp. 'zbiorowisko wody po deszczu', wlkp. 'kałuża powstała na skutek deszczu' (sGP PANKart), kasz. plëta 'woda deszczowa nie mająca odpływu, kałuża' (SychtaKasz, t. 4: 76). Powyższa semantyka jest poświadczona także w derywatach, na przykład w kasz. apelatywie plutnica oznaczającym 'zbiornik wody deszczowej, sadzawkę' (SGP PANKart; SGPKarł, t. 4: 128-129), por. przen. 'coś rozlanego': kasz. plëta 'coś, co jest rozlane’ zecko zrobiło plëtą, žałnère leželë v plëtax vlåsnè krv́i;

(e) powódź: pol. arch. pluta 'powódź: Czterech ludzi, białychgłow, nie kładąc w komputy weszło $w$ korab uchodzac Potopowey pluty (KartXVII), ewentualnie także dłuż. plutal plut 'fala, wylew, powódź' (Muka 1911-1928, t. 2: 82).

Rzeczownik i pochodne od niego derywaty stały się podstawą hydronimów nazywających wody stojące, na przykład niewielkie stawy, jeziorka:

(a) Pluta, staw we wsi Kwilina, pow. włoszczowski, woj. świętokrzyskie (Rymut HE XVI: 229);

(b) Pluta, gwar. kaszub. Plëta, stawek we wsi Chojny w pow. kartuskim (Makowska 1981: 337); 
(c) Pluta, teren podmokły koło wsi Wierzchucino, gmina Krokowa, powiat pucki, województwo pomorskie (Belchnerowska HE VII: 123);

(d) Gluta ${ }^{1}$ (Pluta) jezioro koło wsi Włościejewki, znajdującej się w gminie Książ Wielkopolski, w woj. wielkopolskim (Kozierowski 1916: 180; Borek 1983: 119).

Na podstawie powyższych informacji można przypuszczać, że * pluta była pierwotnym nomen actionis określającym proces lania się, rozlewania, wylewania cieczy. Wymienione wyżej znaczenia powstały w drodze późniejszej konkretyzacji. Należy zauważyć, że zasięg płnsłow. * pluta 'coś rozlanego; powódź; bajoro, kałuża; ulewny deszcz' jest mocno ograniczony. Wyrazy w znaczeniu 'dżdżysta pogoda' są rozpowszechnione głównie w języku polskim (mają niemal ogólnopolski zasięg), kaszubskim oraz dialekcie wschodniosłowackim. Brakuje odpowiedników w języku rosyjskim oraz górnołużyckim. Jeśli interesują nas tylko te słowa, które są bezpośrednimi kontynuantami formy psł., to zasięg jest dodatkowo ograniczony z powodu prawdopodobieństwa, że część leksyki północnosłowiańskiej stanowią wewnętrzne pożyczki słowiańskie. Poświadczenia północnosłowackie, występujące w pasie wzdłuż granicy z Polską, oraz laskie mogą być wynikiem wpływu gwar polskich lub wschodniosłowackich. Podobnie wschodniosłowiańskie wyrazy (brus. i ukr.) mogły się pojawić pod wpływem języka polskiego lub dialektu wschodniosłowackiego.

Problematyczna jest przynależność do dziedzictwa prasłowiańskiego dawnego dłuż. plut ż. Obok formy plut wyjątkowo jest też poświadczony wariant pluta. Zagadnienie etymologii tych wyrazów zostało poruszone przez Heinza Schustera-Šewca w Historyczno-etymologicznym słowniku języków łużyckich. Badacz uważa, że najprawdopodobniej słowo plut 'powódź, fala, przypływ' jest niemiecką pożyczką (niem. Flut 'powódź'), jednakże dopuszcza jako alternatywę pokrewieństwo z pol. pluta (Schuster-Šewc 1978-1989, t. 15: 1108). Zdaje się, że paralele semantyczne w XVII-wiecznej polszczyźnie i w kaszubszczyźnie oraz obecność innych pokrewnych form wymienianych przez autora (np. plutacy 'fließend') pozwalają uznać wyraz za rodzimy.

Warto przytoczyć rozważania W. Kupiszewskiego z cytowanej powyżej pracy, który zauważa, że najwcześniejsze zabytki staropolskie określają pojęcia związane ze słotą w sposób opisowy, a takie nazwy, jak pluta, pluskota, pluskotna pogoda, wilgotne czasy, mokwa, szaruga, pojawiają się później (w XVI i XVII w.) (Kupiszewski 1969: 36-38, 119). W nawiązaniu do powyższego stwierdzenia autora należy jednak zaznaczyć, że nie uwzględnił on najstarszego źródła z połowy XV wieku, w którym został wymieniony po raz pierwszy leksem pluta. Pozostałych nazw natomiast zgodnie z twierdzeniem W. Kupiszewskiego Słownik staropolski nie odnotowuje. Świadczy to o dawności funkcjonowania wyrazu pluta w języku polskim jako terminu meteorologicznego.

Podsumowując analizę kontynuantów płnsłow. * pluta w poszczególnych językach, warto zauważyć, że mimo archaicznej budowy wyrazu jego zasięg jest ograniczony, a znaczenie 'deszczowa pogoda’ stanowi lokalną innowację (nieobecną w języku dłuż.), poświadczoną w języku staropolskim już w połowie XV wieku. Biorąc pod uwagę powszechność wyrazu w dialekcie wschodniosłowackim, należy wykluczyć możliwość lokalnego zapożyczenia z polszczyzny. Zasięg terminu określającego 'czas słoty' zdaje się raczej wskazywać, że powyższe słowo należy 
uznać za dawną polsko-wschodniosłowacką (względnie - przez wzgląd na odrębność języka kaszubskiego - lechicko-wschodniosłowacką) zbieżność leksykalno-semantyczną (Bednarczuk 2018: 178-185). Przy założeniu rodzimości wyrazu ukraińskiego wyraz może stanowić także jedną z paralel polsko-wschodniosłowacko-ukraińskich (zob. Dzendzelìv'kij 1969).

\section{Skróty}

arch. - archaiczny

brus. - białoruski

dial. - dialektalny

dłuż. - dolnołużycki

kasz. - kaszubski

kielec. - kielecki

łac. - łaciński

młp. - małopolski

mn - liczba mnoga

$\mathrm{n}$ - rodzaj nijaki

niem. - niemiecki

ogsła. - ogólnosłowacki

pie. - praindoeuropejski

płnsłow. - północnosłowiański

podkarp. - podkarpacki

ros. - rosyjski

stind. - staroindyjski

stpol. - staropolski

ukr. - ukraiński

wlkp. - wielkopolski

wschsła. - wschodniosłowacki

$\dot{\mathrm{z}}$ - rodzaj żeński

Bibliografia

ASJ: Atlas slovenského jazyka, red. A. Habovštiak, t. 4, Veda, Bratislava 1984.

ASJKom: Atlas slovenského jazyka. Úvod - Komentáre - Dotaznik - Indexy, red. A. Habovštiak, t. 4, Veda, Bratislava 1984. Bartoš, F. 1906: Dialektický slovník moravský, České akademie císaře Františka Josefa pro vědy, slovesnost a umění, Praha. Bednarczuk L. 2018: Początki i pogranicza polszczyzny, Lexis, Kraków.

Belchnerowska HE VII: A. Belchnerowska, Die Namen der stehenden Gewässer im Zuflußgebiet der Ostsee zwischen unter Oder und Weichsel/Nazwy jezior $w$ dorzeczu Bałtyku między dolna Odra i dolną Wisła, Franz Steiner Verlag, Stuttgart 1991.

Biela J. 1882: Gwara zebrzydowska. Studyjum dyjalektologiczne, „Rozprawy i Sprawozdania z Posiedzeń Wydziału Filologicznego Akademii Umiejętności”, seria I, t. 9, Kraków, s. 149-217.

Borek H. (red.) 1983: Hydronimia Odry. Wykaz nazw w układzie hydrograficznym, Instytut Śląski, Opole.

Boryś W. 2005: Słownik etymologiczny języka polskiego, Wydawnictwo Literackie, Kraków.

Brückner A. 1895: Średniowieczna poezya łacińska w Polsce, cz. 2, „Rozprawy Akademii Umiejętności. Wydział Filologiczny", seria II, t. 7, s. 1-62.

Brückner A. 1970: Słownik etymologiczny języka polskiego. Warszawa: Wiedza Powszechna.

Buffa F. 2004: Slovník šarišských nárečí, Nauka - Gustav Moško, Prešov.

Dzendzelìvs'kij J.O. 1969: Ukraïns'ko - zahidnoslov'âns'ki leksični paraleli, Naukova dumka, Kiïv. 
ESBM: Ètymalagičny sloǔnik belaruskaj movy, red. V.U. Martynaǔ, G.A. Cyhun, t. 1-14, Mìnsk: Navuka ì tehnika 1978-. ESUM: Etimologičnij slovnik ukraïns'koï movi, red. O.S. Mel’ničuk, t. 1-6, Naukova dumka, Kiïv 1982-2012.

Ferenčíková, A. 2005: Prší, prší, len sa leje, [w:] K. Balleková, M. Smatana (red.), Zo studnice rodnej reči, Veda Vydavatel'stvo

Slovenskej akadémie vied, Bratislava, s. 29-32.

Grìnčenko B.D. 1958: Slovar' ukraïns'koï movi, t. 1-4, wyd. 2, Vidavnictvo Akademï Nauk URSR, Kiïv.

HSBM: Gìstaryčny sloǔnik belaruskaj movy, red. A.I. Žuraǔskì (t. 1-14), A.M. Bulyka (t. 15-37), Navuka ì tehnìka (t. 1-14),

Belaruskaja Navuka (t. 15-37), Mìnsk 1982-2017.

HSSJ: Historický slovník slovenského jazyka, red. M. Majtán, t. 1-7, Veda, Bratislava 1991-2008.

Kálal M. 1924: Slovenský slovník z literatúry aj nárečí, Slovenská Grafia, Banská Bystrica.

KartXVII: kartoteka Słownika języka polskiego XVII wieku i 1. połowy XVIII wieku (online: http://rcin.org.pl/dlibra/; dostęp:

30 września 2020).

Kazmíř S. 2001: Slovník valašského nářč́í, Dalibor, Malina.

Kozierowski S. 1916: Badania nazw topograficznych dzisiejszej Archidyecezyi Poznańskiej, Towarzystwo Przyjaciół Nauk Poznańskiego, Poznań.

Krajčovič R. 1974: Slovenčina a slovanské jazyky. Praslovanská genéza slovenčiny, Slovenské pedagogické nakladatel’stvo, Bratislava.

Králik L. 2015: Stručný etymologický slovník slovenčiny, Vydavatel'stvo Slovenskej akadémie vied, Bratislava.

Kupiszewski W. 1969: Słownictwo meteorologiczne w gwarach i historii języka polskiego, Zakład Narodowy im. Ossolińskich, Wydawnictwo Polskiej Akademii Nauk, Wrocław.

L.: S.B. Linde, Słownik języka polskiego, t. 1-6, Drukarnia Xx. Pijarów, Warszawa 1807-1814.

Machek V. 1957: Etymologický slovník jazyka českého a slovenského, Nakladatelství Československé akademie věd, Praha. Makowska K. 1981: Toponimia byłego powiatu kartuskiego, praca doktorska pod kierunkiem H. Górnowicza Instytut Języka Polskiego Uniwersytetu Gdańskiego (maszynopis znajdujący się w Pracowni Toponomastycznej Instytutu Języka Polskiego Polskiej Akademii Nauk w Krakowie).

Muka E. 1911-1928: Słownik dolnoserbskeje rěcy a jeje narěcow, t. 1-3, Ruská akademie věd, Česka akademie věd, PetrohradPraha.

Ostrowski B. 2013: Białoruskie gwary Grodzieńszczyzny. Wybrane zagadnienia, Instytut Języka Polskiego Polskiej Akademii Nauk, Kraków.

Pluta F. 1973: Słownictwo Dzierżysławic w powiecie prudnickim, Państwowe Wydawnictwo Naukowe, Wrocław.

Pogwizd S. 2019: Wybrane przykłady polsko-wschodniosłowackich zbieżności, semantycznych na tle ogólnosłowiańskim (wsch.-sła. skura, cma, chudoba, hodovac), „Język Polski” XCIX, nr 3, s. 98-106.

Pokorny J. 1949-1969: Indogermanisches etymologisches Wörterbuch, t. 1-2, A. Francke Verlag, Bern.

R.Mat.: Rječnik hrvatskosrpskoga književnog jezika, red. L. Jonke, M. Stevanović, t. 1-6, Matica hrvatska-Matica srpska, Zagreb-Novi Sad, 1967-1976.

Rymut HE XVI: K. Rymut, Gewässernamen im Linken Zuflußgebiet der Weichsel zwischen Pilica und Brda (Nazwy wodne w zlewisku lewych dopływów Wisły od Pilicy po ujście Brdy), Franz Steiner Verlag, Suttgart 2001.

Schuster-Šewc H. 1978-1989: Historisch-etymologisches Wörterbuch der ober- und niedersorbischen Sprache, t. 1-24, vEB Domowina-Verlag, Bautzen.

Scâškovič T.F. 1983: Sloŭnik Grodzenskaj voblasci, Navuka ì Tehnika, Mìnsk.

SEK: W. Boryś, H. Popowska-Taborska, Stownik etymologiczny kaszubszczyzny, t. 1-6, Slawistyczny Ośrodek Wydawniczy, Warszawa 1994-2010.

SGM: Słownik gwar małopolskich, red. J. Wronicz, t. 1-2, Instytut Języka Polskiego Polskiej Akademii Nauk, Kraków $2016-2017$. SGP PANKart: kartoteka Słownika gwar polskich (online: http://rcin.org.pl/dlibra/).

SGPKarł: J. Karłowicz, Słownik gwar polskich, t. 1-6, nakł. Akademii Umiejętności, Kraków 1900-1911.

SJPDor: Słownik języka polskiego, red. W. Doroszewski, t. 1-11, Państwowe Wydawnictwo Naukowe, Warszawa $1978-1981$.

Slavinec'kij E., Korec'kij-Satanovskij A. 1973: Leksykon latins'kij Ê. Slavynec'kogo. Leksykon Sloveno-latins'kij Ê. Slavynec'kogo ta A. Korec'kogo-Satanovskogo, W.W. Nìmčuk, Kiïv.

Sławski F. 1976: Zarys słowotwórstwa prasłowiańskiego (ciąg dalszy), [w:] idem (red.), Słownik prasłowiański, t. 2, Zakład Narodowy im. Ossolińskich, Wydawnictwo Polskiej Akademii Nauk, Wrocław-Warszawa-Kraków, s. 13-6o.

SPXVI: Słownik polszczyzny XVI wieku, red. M.R. Mayenowa (t. 1-34), K. Mrowcewicz (t. 35-38), t. 1-22, Zakład Narodowy im. Ossolińskich, Wydawnictwo Polskiej Akademii Nauk, Wrocław-Warszawa-Kraków 1966-1994, t. 23-38, Instytut Badań Literackich Polskiej Akademii Nauk, Warszawa 1995-2020. 
SPZB: J.F. Mackevič, Sloŭnik belaruskih gavorak paŭnočna-zahodnâj Belarusi i âe pagraničča, t. 1- 5, Navuka ì tehnìka, Minsk 1979-1986.

SRNG: Slovar' russkih narodnyh govorov, red. F.P. Filin, t. 1-50, Nauka, Moskva 1965-.

SsJ: Slovník slovenského jazyka, red. Š. Peciar, t. 1-6, Vydavatelstvo Slovenskej akadémie vied, Bratislava 1959-1968.

SsJČ: Slovník spisovného jazyka českého, red. J. Bělič, t. 1-4, Nakladatelství Československé akademie věd, Praha 1960-1971. SSN: Slovník slovenských náreči, red. I. Ripka, t. 1-2, Veda, Bratislava 1994-.

sstp: Słownik staropolski, red. S. Urbańczyk, t. 1-9, Zakład Narodowy im. Ossolińskich, Wydawnictwo Polskiej Akademii

Nauk, Wrocław-Warszawa-Kraków 1953-1987, t. 10-11, Instytut Języka Polskiego Polskiej Akademii Nauk, Kraków 1988-2002.

Stanislav J. 1935: Pôvod východoslovenských nárečí, Nákladem Učené společnosti Šafaříkovy, Bratislava.

Stieber Z. 1950: Problém pôvodu východoslovenských nárečí, „Svojina”, Košice (w pol. tłum. Problem pochodzenia dialektów wschodniosłowackich), [w:] Z. Stieber, Świat językowy Słowian, Państwowe Wydawnictwo Naukowe, Warszawa 1974, s. 191-203.

suM: Slovnik ukraïns'koï movi, red. İ.K. Bìlodìd, t. 1-11, Naukova dumka, Kiïv 1970-1980.

SwJP: Słownik współczesnego języka polskiego, red. B. Dunaj, Wilga, Warszawa 1996.

SychtaKasz: B. Sychta, Słownik gwar kaszubskich na tle kultury ludowej, t. 1-7, Zakład Narodowy im. Ossolińskich, Wydawnictwo Polskiej Akademii Nauk, Wrocław 1967-1976.

Štolc J. 1994: Slovenská dialektológia, Veda, Bratislava.

TSBLM: Tłumaczal'ny sloŭnik belaruskaj litaraturnaj movy, red. I.L. Kapyloŭ, Belaruskaja Encyklapedyja imia Petrusìa Broŭkì, Mìnsk 2016.

TSBM: Tlumaczal'ny sloŭnik belaruskaj movy u pâci tamach, red. M.P. Loban, t. 1-5, Galoŭna redakcyja belaruskaj saveckaj encyklapedyì, Minsk 1977-1984.

WSJP PAN: Wielki słownik języka polskiego PAN, red. P. Żmigrodzki (online: http://wsjp.pl; dostęp: 30 września 2020). Želehovskij E., Nedil'skij S. 1886: Malorusko-nimeckij Slovar', Drukarnâ Tow. im Šewczenka, L'vìv.

Summary

\section{Etymology and the semantic development of the word pluta ('wet weather') - an example of parallels in meteorological terminology in the Polish language and in the East Slovak dialect}

Keywords: pluta, East Slovak dialects, etymology, meteorological terminology.

The text discusses an example of a lexical unit which is common to the Polish language and the eastern Slovak dialect. A lexical-semantic analysis of the Polish pluta 'wet weather' and the East Slovak pluta/pluta 'idem' is conducted in the all-Slavic context. Research utilizes dictionary materials, linguistic atlases and index cards of dictionaries. Apart from the basic meaning which denotes wet weather, the lexeme also refers to objects and phenomena associated with water, wetness, e.g. fords, puddles, small ponds, little lakes, floods. It is also the basis of certain hydronyms. The article discusses the problem of etymology. The proto-form is constituted by ${ }^{*}$ pluta, which is derived from the PIE root ${ }^{*}$ pleu- 'to flow, to stream, to overflow'. The word is compared with the descendants of the cognate Proto-Slavic homonym ${ }^{\star}$ pluta. The northern Slavic ${ }^{\star}$ pluta has a much more limited range. Considering the possibility of borrowing to the Ukrainian and the Belarusian language and the ambiguous etymology o the Lower Sorbian plut/pluta, the word in question most likely constitutes a common Polish-eastern Slovak lexical-semantic innovation. 